\title{
Una iconografía del ojo en Emak Bakia
}

\section{Iconography of the eye in Emak Bakia}

\author{
Ainamar Clariana Rodagut \\ Universidad Pompeu Fabra, España \\ ainamar.clariana@gmail.com
}

- Resumen - este artículo es un análisis de la obra cinematográfica Emak Bakia centrado en el motivo del ojo. Su hipótesis es que en esta obra la alusión al ojo hace referencia al concepto de visión. Con la finalidad de validar la hipótesis se utiliza el método hermenéutico. Por esta razón, se realiza una iconografía del ojo que se extiende a parte de la obra fotográfica de Man Ray, para finalizar en la obra elegida.

Palabras clave: ojo, visión, vanguardia, imaginación, espontaneidad.

- Abstract - The following paper is an analysis of the film Emak Bakia. It focuses on the motif of the eye. The hypothesis maintains that the eye in Emak Bakia refers to the concept of vision. In order to prove this hypothesis, the article will use hermeneutics. For this reason, we will explore an iconography of the eye that develops from the photographic work of Man Ray to the work previously mentioned.

Keywords: Eye, Vision, Avant-garde, Imagination, Spontaneity. 
El motivo visual del ojo aparece en muchas obras realizadas por artistas que se incluyen dentro de la corriente estética del surrealismo. Este motivo adquiere especial relevancia en la obra de Max Ernst. Su ojo atravesado por un hilo, portada del poemario de Paul Eluard Repetitions, ha sido descrito por Werner Spies como un manifiesto visual del surrealismo. El mismo autor, en su obra Max Ernst: collages: the invention of the surrealist universe, considera que el ojo rebanado que Luis Buñuel y Salvador Dalí ruedan para Un perro andaluz es una alusión al primer ojo de Max Ernst. El autor introduce una hipótesis abriendo un nuevo campo de investigación para los estudios de vanguardia: «Sin embargo, la destrucción de la mirada no es un motivo sádico, sino una agudización del foco del ojo que resuena en temas como «la visión de la mente», segunda mirada, sueño, visión más allá de lo mundana, ceguera del visionario ${ }^{1} »(112)$.

Esta afirmación forma parte de las citas que la escritora Victoria Cirlot incluye en su obra La visión abierta: del mito del Grial al surrealismo, donde compara la obra de Hildegard von Bingen, mística medieval, con la obra de algunos surrealistas, entre ellos, Max Ernst. El tema fundamental de la comparación gira en torno al concepto de visión abordado en obras anteriores. Sin embargo, Ernst considera la aparición del ojo como una alusión a la visión interior del artista provocada por su creatividad. A raíz de la cita a Spies, Victoria Cirlot apunta que este rebanar del ojo en Un perro andaluz, cuyo antecedente se sitúa en la obra de Ernst, puede interpretarse como: «el sacrificio del ojo exterior en aras del nacimiento del interior» (22).

Las reflexiones citadas anteriormente conforman la hipótesis de este artículo. El objetivo será comprobar si los ojos en Emak Bakia hacen referencia al concepto de visión o no. Para cumplir este objetivo, utilizaremos el método hermenéutico. En primer lugar, se buscarán las claves para la interpretación de la obra dentro de ella misma, para luego ampliar el campo de visión hacia otras obras de Man Ray. Por último, se establecerán comparaciones con obras de otros autores dentro del mismo contexto.

\section{1 CONTEXTO DE LA OBRA}

Película muda rodada en blanco y negro de una duración de 19 minutos, realizada por Man Ray en 1926, año en que el autor produce su primera película: Le Retour á la raison. Emak Bakia fue proyectada por primera vez en el Palacio des Ursulines durante el año de su realización. En el evento, Man Ray le indicó a un grupo de músicos presentes qué debían tocar y en qué momento. Asimismo, se reprodujeron fragmentos de jazz en un fonógrafo, aunque algunos de estos fragmentos no entraban en el repertorio de los músicos. A la proyección de Emak Bakia asistieron muchos participantes vinculados al grupo surrealista, los cuales no estuvieron muy

\footnotetext{
Yet this destruction of the sense of sight is not a sadistic motif but a symbol for an alteration of vision, a sharpening of the eye's focus which sounds the themes of «the mind's eye», second sight, dream, vision beyond the mundane, blindness of the visionary.
} 
entusiasmados con la película. El autor atribuye este fracaso a la libertad, juzgada como individualismo, que él se había tomado durante la grabación de la obra: no había informado a ninguno de sus amigos de estar realizándola. En el artículo citado, Man Ray también se lamenta de la forma sectaria en que el grupo decidía qué obras eran representativas de su movimiento. Si un artista se reunía con el resto del grupo cuando acababa su pieza para comentarla, al día siguiente se publicaban artículos o firmas a favor de la cualidad surrealista de la obra. Sin embargo, en el caso de que la creación no fuera presentada al grupo, su acogida entre los miembros no era del todo afable. El director afirma que, al margen de las consideraciones de la comunidad surrealista, él había realizado la película siendo fiel a los principios del movimiento. En 1963 escribió un artículo titulado «Film dada et surréalisme» que se puede encontrar en la obra L'Occhio tagliato (76-7). En este escrito, Man Ray afirma: "Yo había sido fiel a todos los principios surrealistas: irracionalidad, automatismo, secuencias psicológicas y oníricas, aparentemente desprovistas de lógica, y desprecio total por el arte tradicional de contar una historia» (77).

En este artículo, el artista desarrolla algunas consideraciones personales sobre Emak Bakia. Al hacer referencia a la frase «la raison de cette extravagance», la cual aparece casi al final de la película, asegura que aparece únicamente con la finalidad de tranquilizar al espectador, al igual que el título de su primera película: Retour à la raison. Según el autor, se trataba de engañar al espectador con imágenes que serían explicadas a partir del título. El artista continúa haciendo referencia al discurso que dio en la sala Ursulines una vez finalizada la proyección de Emak Bakia. En la explicación de la charla señala que hizo especial hincapié a que la película no era ninguna historia, que carecía de guion y que no podía calificarse como una película experimental. Su conferencia acaba: «lo que ofrecía al público era la obtención definitiva de una manera de pensar tanto como de ver» (77).

La mirada, según Man Ray, es incompatible con el relato, historia o guion ya que estas formas tienen una estructura interna cuyas partes cumplen una función predeterminada en la obra. Aparte de la introducción, nudo y desenlace que comparte con el relato y la historia, el guion posee lo que se denomina giros. Estos tienen la función de mantener al espectador en vilo sobre el desenlace de algún tema, antes de introducir un nuevo elemento a la historia con la finalidad de que estos no pierdan la atención. Para que los mecanismos puedan desarrollarse correctamente, deben ser previstos por el guionista o escritor antes de iniciar la escritura.

Man Ray parece aludir al episodio ocurrido con Jacques Rigaut para justificar que no piensa lo que quiere contar antes del proceso de creación de sus obras cinematográficas. Ray no tiene inicialmente la voluntad de transmitir algo concreto al espectador, ya que esto requeriría de una estructura de comunicación eficaz. Por el contrario, Man Ray elabora una forma personal de ver y de pensar que no requiere de una planificación previa. Esto no quiere decir que su obra carezca de estructura; significa que esta no se determina de antemano, no hay un plan de rodaje. La 
estructura conforma durante el proceso de creación, tanto en el rodaje como en el montaje. Los elementos que influyen durante la producción no están bajo el control del artista. De hecho, fomenta su participación espontánea la cual queda plasmada en la obra final. Man Ray utiliza el cine para movilizar sus descubrimientos fotográficos. Sus obras cinematográficas no se consideran como encargos. Man Ray escribe: «en el fondo el cine no me interesaba: no tenía ningunas ganas de convertirme en un realizador de éxito. Solo me hubiera apetecido hacer otra película si hubiese tenido fundos ilimitados como para tirar por la ventana» (80).

Después de Emak Bakia, rodó otra película a petición del vizconde de Noailles, quien también había financiado L'Âge d'or y La sang d'un poète. El vizconde quedó fascinado con Emak Bakia y le suplicó que filmara una reunión entre amigos en su castillo. En un principio, el artista rechazó el encargo, pero el conde intentó disuadirlo ofreciéndole libertad absoluta a la hora de filmar y un equipo completo de grabación. Finalmente aceptó, a cambio de la libertad creativa que el vizconde le concedía, así como por la amistad que compartían, antes que por la desmesurada cantidad de dinero ofrecida. Esta obra acabaría siendo Les Mystères du Château de Dés.

En Autorretrato², Man Ray relata que los primeros planos para la película se le ocurrieron camino al castillo. No había planificado nada cuando inició su ruta hacia lo que iba a ser su localización de rodaje. En el coche, vislumbró un paisaje que le llamó la atención y le pidió a su asistente que lo grabara. Tal como explica el autor, el paisaje no le inspiró el resto de la película, únicamente incitó su curiosidad. De este modo, rodó ese plano sin siquiera preguntarse la función que cumpliría en la película.

Estas declaraciones, junto a las citadas anteriormente, describen la postura de Man Ray frente al arte cinematográfico. Su obra artística mantiene una relación indisociable con su propia vida, premisa que responde a los principios surrealistas: la obra adquiere forma en paralelo a la vida. Esta forma de abordar el proceso creativo disminuye la importancia de la voluntad en el artista. Al no tener la pretensión de transmitir algo concreto al espectador, Man Ray desarrolla un trabajo sobre la espera. En su explicación sobre la grabación del paisaje desde el coche, el artista devela la importancia de la atención. De este modo, el azar, por ende la vida, pueden cumplir con la función que les había otorgado el movimiento surrealista. Tal como Max Ernst reflexiona en el artículo «Qu'est-ce que le surréalisme», escrito en 1934, el papel del artista como genio, idea arrastrada desde el romanticismo, se había acabado (cit. en Cirlot, Hildegard von Bingen y la tradición visionaria de occidente 193).

Publicado por primera vez con el título Self Portrait en 1963 por Andre Deutsch en Londres. Aquí citamos la versión española, publicada en Alba Editorial en 2004. 


\section{2 ICONOGRAFÍA DEL OJO EN LA OBRA DE MAN RAY}

El tema de los ojos y del voyerismo, en el que se centrará el análisis de la película Emak Bakia, está presente en toda la obra de Man Ray. El artista tiene dos formas de hacer referencia al ojo en su obra. Por una parte, en algunos de sus autorretratos, Ray se representa con los ojos cubiertos por un lente. En otros, cubre sus ojos con anteojos o con el lente de una cámara. Esta reflexión sobre la relación entre ojo y mirada se repite en dos objetos en los cuales Man Ray invita al espectador a cubrir sus ojos con un elemento que altera el campo de la visión (Le Voyeur y Optic-topic). El ojo aparece en la obra como elemento individual que crea un objeto nuevo cuando se suma a otro. En este último caso, el ojo, como objeto, tiene un significado por sí mismo en lugar de representar la mirada del artista.

El ojo aparece en una de las obras fundamentales de Man Ray, Object to Be Destroyed, o en su reproducción posterior, Object Indestructible. En esta última obra, hay un ojo pegado a un metrónomo. Tristan Tzara, en el dorso de un diseño de 1932 donde aparece el mismo metrónomo, escribió: "Corta el ojo de una fotografía de un amante que ya no se observa. Pon el ojo en el péndulo del metrónomo y regula el peso para crear el tempo deseado. Siga hasta el límite de tolerancia. Con un martillo, apúntelo y trate de destruir el objeto de un solo golpe» (cit. en Penrose 109).

Tal como escribe Sylvia Metz en Surreal Objects: three-dimensional works from Dali to Man Ray, Man Ray utilizaba el metrónomo para trabajar al ritmo que este marcaba: «El ojo suponía crear una ilusión del observamiento al pintar, mientras, al mismo tiempo, representa a Ray mismo» (251). El ojo del metrónomo marca un ritmo regular para resaltar la idea de control que después reaparecerá en otro objeto que retoma este motivo: Le Temoin. Esta obra consiste en una caja con forma oval en cuya superficie hay un ojo dibujado. A través del título, el artista piensa al ojo como observador, controlador, captador y testigo de lo que sucede.

A lo largo de su obra, Man Ray propone dos reflexiones diferentes en torno al ojo: un elemento de unión para crear un objeto nuevo, por lo que el ojo tiene un significado propio como parte de la relación, y un tratamiento de la mirada, suya o del espectador. En el primer caso, el ojo se utiliza como un elemento que, vinculado a otro, hace saltar la chispa que surge cuando dos realidades distantes se juntan. En la entrevista que mantiene con Pierre Bourgeade, Man Ray declara ${ }^{3}$ : Yo no necesito una cosa sino dos cosas. Dos cosas que en sí mismas no tengan relación y que pongo juntas para crear, por contraste, una especie de poesía plástica» (43).

La unión de dos objetos explica la relación entre el metrónomo y el ojo, por un lado, y la caja en forma oval y el ojo, por otra. En el primer caso, mirar es contralar el tiempo. El metrónomo marca el ritmo elegido, pero es el ojo el que decide el ritmo, como paso del tiempo. Según las declaraciones de Man Ray, el tiempo equivale a la velocidad de trabajo del artista. En Le Temoin, una caja cerrada tiene, en una de

El libro de Pierre Bourgeade consiste en una entrevista al artista y algunos textos del mismo al final. 
sus superficies, el dibujo de un ojo. La caja, cuyo interior no se muestra al espectador, alude al misterio ${ }^{4}$; el ojo-testigo guarda en su interior lo que no se revelará al espectador, por lo que el objeto solo es testigo de sí mismo.

Le Temoin y Object Indestructible son objetos que «afectan al observador a partir de su propia existencia, pero que ya no depende de la voluntad de su creador como resultado de una «creación artística»» (Haus s/n). La unión entre el metrónomo y el ojo marca el transcurrir de un tiempo que podría sucederse eternamente sin necesidad de una voluntad externa. El ojo-testigo registra una realidad que guarda en su interior para si, lo cual crea el misterio para quien lo observa, lo cual equivale al control del objeto y al descontrol del espectador. Según declaraciones de Man Ray, que aparecen en la obra Surreal objects «en un momento en que el metrónomo dejó de funcionar no dudé en destruirlo para construir otro posteriormente» ${ }^{5}(252)$.

Los objetos con ojos, que el artista construye para representar la idea de sentirse observado, responden, en una primera instancia, a la relación que el artista tiene consigo mismo en la fase de creación, pero después adquieren presencia de manera autónoma. Sin embargo, el ojo sigue siendo representate exclusivo de un solo alcance: la mirada. No se habla del ojo como un elemento externo que cumple una función determinada: es una reflexión sobre la visibilidad. En estos casos, el ojo forma parte de un conjunto, de un individuo:

Man Ray volvió a retomar algunos temas utilizados en el pasado. El ojo y el voyeurismo, motivos que le habían fascinado durante muchos años y que quedaron plasmados en obras como Object to Be Destroyed y The Witness [...], resucitan en Le Vouyeur, una caja con un agujero que invita a los espectadores a mirar en un escondite secreto [...]. Por el contrario, Optic-Topic [...] y The Mask son esculturas que han de colocarse sobre los ojos, impidiendo la visión de quien las lleva (McCullin 33).

En la obra de Man Ray hay similitudes importantes entre la forma en que él representa la mirada en los autorretratos y en la del espectador de sus objetos. En ambos casos, los ojos están cubiertos por algo externo a la persona que mira. En muchos de sus autorretratos, hay lentes que cubren sus ojos. En algunos objetos, el artista invita al espectador a cubrir su mirada de diferentes formas. Por otro lado, en otros retratos fotográficos, las personas mantienen los ojos cerrados. Estos son, por ejemplo, los casos de Lee Miller, 1930; Jacqueline Goddard, 1932; Nush Eluard, 1935; y Consuelo y Saint Exúpery, 1930.

Hay dos objetos a través de los cuales el artista invita al espectador a participar de su reflexión en torno a la mirada. Ambos hacen referencia explícita al título: Le Vouyeur y Optic-Topic. Le Vouyeur consiste en una caja de madera con un agujero en la parte superior derecha. Una flecha indica la perforación junto al título 'Le Vouyeur', invitando al espectador a mirar. Pero aunque el espectador mire a través del agujero, no verá lo que hay en la caja, ya que esta no contiene luz en su interior.

$4 \quad$ Este tema será tratado también por Luis Buñuel en la mítica caja de Belle de Jour. El director siempre declaró que lo que hubiera en esa caja corría a cuenta de la imaginación del espectador.

5 La traducción es mía, el texto original está en inglés. 
Esto representa el misterio antes señalado. Optic-Topic es una máscara de metal con perforaciones muy pequeñas. En esta obra, Man Ray obstruye, nuevamente, la mirada del espectador con otro elemento. A través de los objetos Optic-Topic y Le Vouyeur, el artista propone al espectador probar la experiencia de mirar la realidad con los ojos cubiertos por algo externo.

Le Vouyeur y Optic-Topic tienen su precedente en el primer autorretrato del autor. En el autorretrato realizado en 1916, dos timbres representan la voluntad de participación del espectador. Según declara el artista en Self-Portrait:

En un fondo de pintura negra y aluminio, puse dos campanas eléctricas y un interruptor. En el medio, simplemente puse mi mano en la paleta y la pintura se convirtió en una firma. Todos los que presionaban el botón se decepcionaban, porque la campana no sonaba. Se me tildó de humorista, pero no era mi intensión ser gracioso. Simplemente quería que el espactador fuese una parte activa de la creación (Penrose 43).

Los ojos de Le Temoin y Object Indestructible son oposiciones del concepto de mirada con las cuales que se invita al espectador a experimentar Le Vouyeur y Optic-Topic. Los primeros tienen las funciones de marcar el tiempo y controlar el uso que se hace del objeto, atestiguando lo que sucede a su alrededor. Ninguno de estos dos objetos tiene algo externo que interfiera en la labor observadora para la que están diseñados. Sin embargo, en sus autorretratos, los ojos del artista están cubiertos por un lente. En la misma línea, el espectador que mire a través de la máscara de Optic-Topic o a través del agujero de Le Vouyeur percibirá su sentido visual obstruido. Pero en Le Vouyeur y Optic-Topic, los ojos están velados, por lo tanto, la función de testigo y control, que según Man Ray por naturaleza se debiera llevar a cabo, se ve alterada.

\section{3 ANÁLISIS CINEMATOGRÁFICO DE EMAK BAKIA}

Este apartado aborda el motivo del ojo en la película Emak Bakia por la especial función que este desempeña en ella. El análisis se divide en tres partes: la autobiografía o la posición del artista frente a la obra; los símbolos y los objetos giratorios; y la secuencia de las mujeres y la última escena. En el primer punto, se considera que el primer plano hace referencia a la representación de la posición del artista dentro de la obra, por lo tanto, a la reflexión que este plantea en torno a la misma. En el segundo apartado, se tratan los objetos rotatorios. En función de estos, se abordan los procesos técnicos que Man Ray utilizó en Emak Bakia y la relación que mantiene con sus fotografías y objetos. Los procesos técnicos permiten establecer una relación entre los objetos rotatorios y los objets trouvés. El tercer punto contiene el análisis de la escena de los cuellos de camisa (con Jacques Rigaut) y la secuencia de las mujeres que abren los ojos, la cual será objeto de un análisis más profundo por la relevancia que adquiere el motivo del ojo en ella. Por la misma razón, el último plano de la secuencia se relacionará con el primer plano de la película. 


\subsection{EL AUTORRETRATO}

En el primer fotograma posterior a los créditos podemos apreciar a Man Ray mirando a través del objetivo de una cámara. La particularidad de esta imagen corresponde al ojo superpuesto sobre ella. El ojo del artista está cercado por el objetivo de este aparato. Por sobre el cuerpo de la misma, aparece un ojo superpuesto.

Man Ray se retrata en el primer fotograma de Emak Bakia. Con la finalidad de comprender la importancia que los diferentes elementos mantienen dentro del cuadro, se pueden observar otras obras de su autoría que aparecen en la imagen. Su Autoportrait de 1931 mantiene una relación con este primer fotograma. En ambas fotografías aparece de perfil, situándose en una posición secundaria, como asistente de cámara. En ambas imágenes, la mirada del artista se dirige a la cámara retratada. Al mismo tiempo, los únicos «ojos» que miran a la cámara son sus lentes, a los que el artista mira. Lo característico de estos autorretratos no es la aparición del aparato fotográfico o cinematográfico en el lugar que debiera ocupar el artista, sino la forma en que este se relaciona con la mirada del autor. En ambos autorretratos Man Ray suple su mirada por la de la cámara, es decir, no es el artista quien mira, es la camara

A propósito de las coincidencias que se han destacado, cabe notar la relación que estos elementos mantienen con Selfportrait (1936) en la obra Les Mains Libres. En este último diseño, el artista se dibuja a sí mismo con unos anteojos, y sus lentes se dividen en proporciones fotográficas. Aunque no se trate de una cámara, como en las imágenes restantes, Man Ray se representa a sí mismo mirando a través de un lente. Los anteojos se convierten en un objeto capaz de hacer divisiones matemáticas. En los tres autorretratos posteriores, realizados en los años 1943, 1947 y 1950, aún queda un rastro de los autorretratos anteriores: el autor divide en cuatro porciones su autorretrato, aludiendo así al canon de la imagen fotográfica. En el primer autorretrato que se conoce, realizado en 1916 (al que antes hemos aludido), se pueden observar ya los anteojos como elemento definitorio del carácter del autor ${ }^{6}$.

Lo que cubre los ojos de Man Ray en todos los autorretratos citados es un lente, bien sea el de una cámara fotográfica (Autoportrait) o cinematográfica (Emak Bakia), o el cristal de unos anteojos (Selfportrait). Lo que comparten las tres características es que se un dispositivo independiente lleva a cabo la función del ojo biológico, es decir, la función es ajena al cuerpo del artista. De este modo, se podría decir que Man Ray simboliza su genio en los lentos, lo cual altera el cometido natural de los ojos, es decir, presente en Object Indestructible y Le Temoin.

Inicialmente, el lente de las cámaras de vídeo y las fotográficas tiene una función utilitaria. En los autorretratos en los que el artista se representa con anteojos, la función del lente cambia. En Selfportrait de 1936 el lente es un objeto útil (caso

\footnotetext{
Pierre Bourgeade hace hincapié en este tema y le pregunta al autor por qué ha añadido anteojos a una máscara que le representa, Man Ray responde: «hoy los anteojos imprimen carácter en una cara, como la barba o el bigote»(28).
} 
de la cámara), pieza imprescindible. De hecho, son indispensables para quien tiene que llevarlas, puesto que sin ellas no vería. Sin embargo, Man Ray trastoca la funcionalidad del aparato, se autorretrata con los lentes por voluntad, representando así la relación con ellos: un vínculo de dependencia. Francis M. Naumann en un artículo titulado "Anarquia Estètica", e incluido en la obra Duchamp, Man Ray, Picabia, escribe:

Puede ser que a través de su Autorretrato con barras en los anteojos aludiera al proceso en el que estaba inmerso: los anteojos [...] le impedían ver con claridad el resultado final de su trabajo, ya que cuando hacía el dibujo Man Ray, no podía saber lo que Éluard escribiría como respuesta a la imagen. Sea como fuere, estos anteojos con barras alteran la comprensión que tiene el artista de su mundo, puede ser que de la misma forma en que lo hace un sueño. Por contra, es probable que Man Ray entendiera que esta especie de anteojos le ayudarían a ver más claramente, puesto que se puede considerar que el dibujo ilustra el tópico según el cual los ojos son ventanas del alma, o, como podría reformularlo un artista, que para un pintor, las ventanas (es decir, los cuadros que pinta) son una ventana al yo (69)

Man Ray necesita los lentes para representarse, lo cual otorga autoridad al objeto. De hecho, en los autorretratos, el artista aparece sujetando una cámara fotográfica, situandose él en segundo plano, cediendo el primer plano a la cámara fotográfica cuyo objetivo es ser el único ojo que «mira a cámara». De este modo, Man Ray otorga protagonismo al aparato para ceder el control que ejerce su ojo al de la cámara. Como consecuencia, lo que quede en la película lo decidirá la cámara, no el artista; la cámara se convierte en su representante.

Man Ray evidencia la cesión del control ${ }^{7}$ a través de la sustitución de la función del ojo físico por el lente, el cual conforma el carácter de la obra. De hecho, en sus autorretratos, representa lo que tantas veces ha declarado, según escribe Bourgeade, «Como él mismo dice: «Nunca he pintado un cuadro reciente». Nunca aprendió, es más: nunca ha buscado. Él ha imaginado. Ha inventado en cada ocasión» (22). Sus creaciones tienen su origen en su imaginación, no en la voluntad de representación mimética de la realidad. En el prefacio, incluido en Man Ray: Fotografías. Paris 1920 1934, Man Ray explica así la procedencia de su obra: «Las imágenes que vienen a continuación tienen por objeto la experiencia, y no la experimentación. Captadas en momentos de liberación visual, en periodos de contacto emotivo, estas imágenes son residuos oxidados de lo que fueron seres vivos» (80). Situarse detrás del lente define su posición frente a la obra y esta nace posteriormente de la liberación de imágenes. De este modo, el estar detrás del lente en Man Ray podría interpretarse como el «lugar de la imaginación».

La renuncia al control que ejerce el ojo físico aparece en el retrato que el artista realizó del Marqués de Sade. Según explica Man Ray, lo creó a partir de descripcio-

Como se ha explicado anteriormente, el ojo desnudo representa el control, tal como veíamos en los objetos citados. 
nes físicas muy concretas, dejando un hueco en el lugar en que debía situarse el ojo izquierdo del escritor. Declara a Pierre Bourgeade: «He falseado un poco para que se vea mejor el ojo. Se había quedado ciego del ojo izquierdo antes de morir. Eso era algo que yo no sabía, y no lo supe hasta después. Fue una especie de premonición» (56).

«El sacrificio del ojo exterior en aras del nacimiento del interior» (21) es una idea tratada por Victoria Cirlot a través del ejemplo de la obra de Víctor Brauner, artista surrealista que acabó su vida con un ojo corporal mutilado. Desde la pérdida del ojo derecho, su obra artística comenzó a ser más introspectiva, el artista creó un mundo personal enriquecido. A raíz de este acontecimiento, la autora considera que el perjuicio de uno de sus ojos físicos potenció su imaginación creadora.

En la obra de la escritora, la alusión al ojo se relaciona con la capacidad visionaria del artista. Aunque el ojo de las obras pictóricas reproducidas es un ojo físico, la representación responde a la necesidad de hacer referencia al despertar del ojo interior. La apertura del ojo interior es el primer paso hacia el «mundo imaginal» del artista, hacia su experiencia visionaria. En el caso de Man Ray, el sacrificio del ojo físico es metafórico, no se trata de una amputación. Sin embargo, en sus autorretratos, el término sacrificio es intercambiable por el de auto-renuncia. La cesión de control que estos manifiestan propicia la liberación de imágenes. Este surgimiento incontrolable de imágenes provenientes de su interioridad (o inconsciente) se expresa en la libertad y originalidad que caracteriza toda la obra de Man Ray. El artista declara:

Me basta con mirar cualquier cosa, y ese algo puede inspirarme de inmediato una idea [...]. No es un documento, no es la impresión misma de ese objeto o de ese acontecimiento. Es el resultado de esta impresión... que brota espontáneamente... Como cuando alguien te ataca y tu respuesta instintiva es devolverle el golpe» (cit. en Bourgeade 70).

Man Ray parte de un objeto externo, sin embargo, el primer paso hacia la creación es el deseo: «El despertar de un deseo constituye el primer paso hacia la participación y la experiencia» (Victoria Cirlot, La visión abierta 79). La escritora piensa la apertura del ojo interior como resultado del deseo de ver según un modo que implica el sacrificio del ojo físico.

El segundo paso hacia la visión es la actitud pasiva frente a la emergencia de imágenes. Por esta razón, Man Ray elegía el lente para situarse detrás, cediéndole el control y adquiriendo así una actitud receptiva, expectante. En esta actitud pasiva, las imágenes afloran de forma espontánea, como si la propia voluntad estuviera al margen de su creación. Declara Man Ray:

Nadie puede decirme qué debo hacer, ni guiarme. Se me puede criticar después, pero es demasiado tarde, para entonces el trabajo ya está hecho. Yo he probado la libertad, y era un trabajo duro pero merecía la pena. [...] El pintor es un ser sagrado [...] Toda opinión es pasajera, pero toda obra es permanente (cit. en Bourgeade 65).

En Emak Bakia, a partir del primer fotograma, el director advierte al espectador que la proyección será el resultado de su visión, que no puede ser de otro modo: visión 
alterada por el lente y, por lo tanto, fuera de su control. La película es fruto de un deseo proyectado en el objeto que lo ha llevado a situarse «en el lugar de la imaginación» ${ }^{8}$.

El primer fotograma de Emak Bakia presenta la película tal como Man Ray la introdujo en su primera proyección: su propia forma de pensar y de ver. Al mismo tiempo, este fotograma tiene la función de avisar al espectador del lugar desde el que este debe mirar la película. Según escribe Man Ray en «Je n’ai jamais...»" “L’ expérience dépend $d u$ spectateur pour autant que sa bonne volonté accepte ce que l'oeil lui transmet. Le succès d'une expérience est proportionné au désir de découvrir et de jouir, et ce désir sera la soule mesure qu'aura de la valeur du peintre le reste de la société» (cit. en Schwarz 48).

Emak Bakia es el resultado de la «participación y la experiencia» de Man Ray de su propia visión, que acontece cuando el artista cede el control de lo representado a la cámara. Puesto que el artista otorga al espectador una posición participativa, este participará de la obra (visión) en la medida en que tenga el deseo de asistir a la experiencia que Man Ray quiere procurarle.

\subsubsection{LOS OBJETOS ROTATORIOS}

Man Ray dedica una gran parte del filme al tratamiento de la luz a través de los objetos que he convenido en llamar rotatorios o giratorios. El mismo artista, al explicar el proceso de grabación de la película, declara que grabó parte de sus objetos inventados. De hecho, los procedimientos técnicos que empleó para grabarlos son los mismos que utilizaba para realizar sus fotografías. Por esta razón, la técnica adquiere relevancia en esta parte del filme, ya que refleja una voluntad de representación no mimética. Por otra parte, en función de dicha técnica, los objetos giratorios son comparables a lo que posteriormente el autor llamará Objects of my affection ${ }^{10}$.

Los objets trouvés se erigen como símbolos. Concebidos a partir del encuentro entre dos realidades distantes, apelan a la intuición del espectador. Ingrid Pfeiffer, en un artículo titulado "Surreal Objects Yesterday and Today», escribe: "Objects of various origins, combined and transformed, found and worked, objects that do not describe or explain, that encounter the viewer openly and intuitively, objects with a mysterious, humorous, or erotic effect» (15).

La técnica que Man Ray utilizó para grabar Emak Bakia permite equiparar los objetos giratorios a los objects trouvés. De todos modos, las técnicas utilizadas ya estaban presentes en su primera película Le Retour á la raison: la sobreimpresión, el

8 Sobre la importancia de implicarse en el proceso creativo, Man Ray explicaba a sus alumnos qué debían hacer para pintar: «Se tú mismo. Sigue tus propios impulsos. Y que sea tu personalidad la que surja ya no podrá confundirse con ninguna otra, jigual que tu cara no puede confundirse con ninguna otra!» (cit. en Bourgeade, 27).

9 He extraído el artículo de un libro titulado Man Ray consistente en una recopilación de artículos, algunos escritos por Man Ray y otros por diferentes surrealistas que hablan de él. El artículo que se cita está fechado en 1945 y su título original es: «It has never been my object...».

10 Según el nombre con el que se titula un catálogo publicado en 1985 por la Zabriskie Gallery. Éste fue realizado a raíz de una exposición celebrada entre enero y febrero del mismo año de su publicación. 
fotomontaje y la rayografía. La última fue introducida en el cine por el autor a raíz de la idea que le proporcionó Tristan Tzara. El escritor fue a su casa para decirle que, al día siguiente, estaba anunciada una película suya en una muestra de artistas que habían organizado. Man Ray, desde que había adquirido su cámara, había grabado algunas imágenes, pero estas eran insuficientes para la película que requería el escritor. Quejándose a Tzara de la velocidad en la que este le estaba exigiendo que acabara su película, el otro le sugirió que hiciera lo mismo que ya había hecho en papel fotográfico: rayografías. El fotógrafo relataba así el proceso:

Compré un rollo de trescientos metros de película, me metí en el cuarto oscuro y recorté el material en tiras cortas, que clavé a la mesa de trabajo. Rocié con sal y pimienta algunas de las tiras, como el cocinero que prepara un asado, arrojé alfileres y chinchetas aleatoriamente sobre otras. Luego encendí la luz un par de segundos, como había hecho para mis rayografías estáticas. A continuación, levanté con sumo cuidado la película de la mesa, la sacudí para eliminar los residuos y la introduje en los tanques de revelado (Man Ray, Autorretrato 323).

La técnica que bautizó con el nombre 'rayograma' viene a ser la misma que László Moholy-Nagy llamó ‘fotograma'. Sin embargo, no existe ningún documento que atestigüe que los artistas tuvieran conocimiento de las obras del otro. De todos modos, el último supo del movimiento surrealista y de la obra de André Breton, citándolos en su libro Peinture, photographie, film et autres écrits sur la photogra$p_{h i e^{11}}$. En esta obra, el fotógrafo establece una teoría del arte fotográfico a partir de la técnica del fotograma, con la finalidad de proponer una relación entre fotografía y pintura abstracta. De hecho, el autor quería quitarle el peso de la representación al arte fotográfico.

Cuando László Moholy-Nagy comenzó a trabajar en sus fotogramas, el arte fotográfico ya tenía una función determinada: liberar a la pintura de la función mimética. La consecuencia fue creer que la fotografía debía 'registrar' objetivamente la realidad. Sin embargo, esta responsabilidad reducía la posibilidad de la libre representación del arte fotográfico. En contra de esta carga, que consideraba injustamente atribuida a la fotografía, László Moholy-Nagy había teorizado ampliamente:

Lo que resulta peculiar es el hecho de que la fotografía, que originalmente fue creada para el registro exacto de la realidad inmediata, pueda convertirse en instrumento de lo fantástico, de lo onírico, de lo suprarreal y de lo imaginario. El ferviente anhelo de penetrar el subconsciente para alcanzar un mayor dominio de los mecanismos de la inspiración es casi con seguridad un aspecto eterno de la condición humana. La fotografía sin cámara, las sobreimpresiones, los prismas, el fotomontaje, la distorsión mecánica o química, el empleo de negativos y la solarización son todos medios legítimos en el campo de la fotografía. Al mismo tiempo pueden servir para crear un lenguaje fotográfico más complejo, acaso el lenguaje «verdadero» al que se refería André Bretón (223).

11 Publicada por primera vez en 1925 bajo el título Malerei, Fotographie, Film por la editorial Albert Langen Verlag en Munich. 
A partir de la reflexión señalada, László Moholy-Nagy desarrolla la técnica del fotograma, la cual consiste en el control de la proyección de luz en un papel fotosensible a través de la superposición de objetos sobre la superficie del papel. El resultado fue una serie de imágenes que no representaban nada concreto y que, posteriormente, se les llama abstractas. Se trata de una inversión de la técnica fotográfica en la medida en que se controla el vaciado de luz. En otras palabras, la superposición del objeto sobre el papel sensible provoca que lo plasmado sea la sombra que proyecta el objeto sobre la superficie. Sin embargo, paradójicamente, la sombra del objeto será la mancha de luz en el papel velado. Situados en contextos diferentes, Man Ray y László Moholy-Nagy desarrollan técnicas idénticas.

Tenemos que señalar que Man Ray repetirá estas técnicas de sobreimpresión, rayogramas y solarización en su primer film Le Retour á la Raison. En él, trata la cinta fílmica como un objeto cotidiano. Sin embargo, en la evolución del artista, este comportamiento reseguía un hilo ya iniciado con los objets trouvés. El someter la cinta fílmica a un cuidado inusual, equiparable al de un objeto de la cotidianidad, por una parte, tenía la intención de burlarse de un espectador que buscara una explicación racional a la obra. Sin embargo, aun lanzando los objetos sin aparente intención consciente, dejaba su vínculo con los objetos en las películas.

Las técnicas utilizadas por Man Ray para grabar los objetos giratorios reflejan su voluntad de no mostrar las cosas tal como se ven. Andreas Haus escribe:

La técnica, dominada de forma profesional y nada pretenciosa, reforzó la base para el programa surrealista del abandono del Yo activo al sueño y en favor del lema Gloire à l'objet!, objeto que afecta al observador a partir de su propia existencia pero que ya no depende de la voluntad de su creador como resultado de una "creación» artística» (Introducción s/n).

En función a la liberación de imágenes y a la forma espontánea en que estas surgen, los objetos de Man Ray, tantas veces definidos como objetos de otro mundo, pueden calificarse como símbolos, en la medida en que forman parte de una realidad desconocida e imposible de clasificar, no solo para el espectador, sino también para el artista. Sin embargo, aunque se trate de obras inexplicables, su observación provoca una vivencia, así los objetos apelan a una parte desconocida e inconsciente del yo. 


\subsubsection{LA SECUENCIA DE LAS MUJERES}

En la última cuarta parte del filme Emak Bakia aparecen cuatro mujeres que abren los ojos frente al objetivo fílmico. Cada una mantiene una actitud diferente frente a la cámara. Las cuatro están grabadas a través de distintos encuadres e iluminaciones. La primera está filmada en plano picado. La segunda, en un encuadre idéntico al de la primera. Sin embargo, en este caso, la cámara graba en un ángulo de 45 grados. La tercera está grabada desde más distancia que las otras y por eso incluye el busto en el encuadre, además, la cámara está situada frente a ella.

Entre todos los planos de las mujeres que abren los ojos transcurren apenas dos minutos. En el minuto 19'00 atendemos a la secuencia más comentada de Emak Bakia. Kiki de Montparnasse está tumbada en un diván. La cámara se acerca. La mujer parece tener los ojos abiertos, sin embargo, estos se revelan extraños. Finalmente, en primer plano, abre sus verdaderos ojos, puesto que encima tiene otros pintados. André Breton, en un texto titulado Los rostros de la mujer, que dedica a Man Ray, escribe: «El retrato de un ser querido ha de poder ser no solo una imagen que merece nuestra sonrisa, sino además un oráculo que despierta nuestras preguntas» (cit. en Man Ray, Fotografías 25) ${ }^{12}$.

Man Ray graba cómo cuatro mujeres abren los ojos. El realizador no se mueve (no hay movimientos de cámara), no invade su espacio (no introduce elementos de manipulación de la imagen), únicamente graba cómo se desarrolla la acción. A partir de esta secuencia de primeros planos, se puede observar que, paulatinamente, el artista se aleja de la mujer. Esta distancia da espacio a la que tiene los ojos cerrados para que se mueva (progresión del primero al cuarto plano de mujeres) paulatinamente.

En el primer plano, el lugar de la cámara no le permite ningún movimiento a la protagonista, ni siquiera el de apartar la mirada, ya que esto la sacaría del encuadre. En el segundo plano, la situación parece más distendida, la joven ríe a pesar de estar aún cercada por el cuadro de la cámara. El tercero de los primeros planos es más abierto e incluye el busto de la mujer, quien al principio está seria y luego sonríe. Finalmente vuelve a su seriedad; parece haber abierto los ojos un momento para volverlos a cerrar. En los dos casos, la extrañeza es precisamente abrir los ojos.

La extravagancia de la última escena, razón por la cual ha sido comentada tantas veces, tiene que ver con los ojos falsos que Alice Prin lleva pintados sobre los suyos. Cuando finalmente abre sus verdaderos ojos, el espectador, que se creía voyerista, se siente rápidamente observado, dominado por algo incontrolable (el personaje), invirtiendo así la situación habitual. Sobre este plano, Juan Miguel Company, en su artículo titulado «Man ray o el desdoblamiento del objeto» e incluido en la obra Surrealistas, surrealismo y cinema, ha escrito:

2 Alice Prin, más conocida por el nombre Kiki de Montparnasse, fue amante y musa de Man Ray durante muchos años y vivieron juntos durante al menos seis años. 
Si la metonimia del ojo/objetivo de la cámara estructura las imágenes del film, será la mirada devuelta por la mujer al hombre -y eludiendo, al paso, la de este la cristalizadora, metafóricamente, del fantasma deseante, instaurando al sujeto dentro de ese código simbólico que para Kristeva es cifra del amor como tal (141).

Como se ha visto, el principio y el final de la película otorgan especial atención al ejercicio de ver: el primer fotograma trata la mirada del artista, del hombre creador; la última secuencia se centra en el ver del personaje. Ambos lados han sufrido un cambio en su percepción visual. Uno mira mientras el otro miente, haciendo creer que se deja ver; pero ni el artista ni el personaje miran sin haberse cubierto primero la vista. En la última escena, Kiki de Montparnasse está durmiendo. Se levanta por un instante y vuelve a caer. De hecho, parecería que se ha levantado para dejar ver su trampa, no porque quiera ver nada en concreto. Al escapar del contacto visual, el personaje se convierte en un enigma que obtiene vida en su secreto. Sin que el director lo haya decidido, el objeto trasciende su propio deseo, se aleja de él adquiriendo una vida propia igual que sucediera con los objetos rotatorios.

\subsubsection{LA ESCENA DE JACQUES RIGAUT Y LA CONCLUSIÓN}

Hay solo una escena con continuidad narrativa en toda la película, a parte de la secuencia (que no es escena) de las mujeres que abren los ojos. En el minuto 16'03, sobre un fondo negro, aparece la siguiente frase escrita con letras blancas: «La raison de cette extravagance». Después de esta sentencia se desarrolla la escena de Jacques Rigaut y los cuellos de camisa. Man Ray relata cómo realizó esta escena:

El instinto Dadá seguía siendo muy acusado en mí. Cuando regresé a París continué con otras tomas en el estudio. Para entonces tenía ya un batiburrillo de tomas realistas, relucientes cristales y formas abstractas obtenidas con los espejos deformantes, casi suficientes para la película. Necesitaba terminarla con algo parecido a un clímax, para que los espectadores no me considerasen demasiado bohemio. Mi película pretendía ser una sátira del cine. Una visita de mi amigo Jacques Rigaut (...) me dio la idea (Man Ray, Autorretrato 338).

Man Ray, a través de la planificación de la escena, induce en el espectador una pregunta: si quien está detrás de la cámara es un personaje más. Tres secuencias de planos relacionados producen la intriga; la imposibilidad del cruce de miradas (arriba y abajo), la distancia entre el dentro y el afuera (escindido por el elemento puerta y el travelling que resalta su función) y, por último, el desencuentro entre los personajes en el último plano de la escena.

La imposibilidad del cruce de miradas entre Jacques Rigaut y el que se sitúa detrás de la cámara surge del lazo que Man Ray crea entre arriba y abajo. En dos planos diferentes, el protagonista sube la mirada: en el primer plano, cuando el coche entra en el cuadro, el protagonista, desde el vehículo, dirige su mirada hacia la cámara en un plano picado. En segundo lugar, cuando la cámara graba al personaje 
desde dentro del local, este vuelve de nuevo la mirada hacia el cielo. La sensación de que existe un personaje que mira desde abajo se consigue a través de un plano contrapicado que sigue a la segunda mirada al cielo del protagonista. Este plano es peculiar porque parece no mantener relación con la planificación de la escena. El plano parece subjetivo, pero no lo es, puesto que si se detiene la película se podrá ver una cabeza que cruza el encuadre y lleva un sombrero igual que el del protagonista. Esto lleva a pensar que el personaje del sombrero es Jacques Rigaut. De este modo, entre el primer plano y el plano contrapicado se establece una voluntad de encuentro, que resulta frustrada, entre el que dirige la cámara (cuya «mirada» es conducida por el objetivo de la misma) y el protagonista.

Hay varias secuencias de planos que apoyan esta idea de desencuentros entre personajes. Por ejemplo, el presentado en el primer vínculo, entre arriba y abajo. La secuencia está compuesta por dos planos repetidos desde dentro del local en los que la comunicación vuelve a ser interrumpida, en este caso por una puerta. El otro ejemplo es el del último plano, que se diferencia de las secuencias de planos anteriores porque el desencuentro se produce entre dos personajes que aparecen en un mismo cuadro. En los dos primeros casos, la dificultad comunicativa se establece entre el protagonista y el posible personaje oculto tras la cámara. Sin embargo, en el plano final, entra un personaje nuevo en la sala que no se comunica con el protagonista. Jacques Rigaut no advierte la entrada del nuevo en la habitación en la que él se encuentra, así que sigue de espaldas a él imposibilitando el encuentro.

Las secuencias de planos descritas mantienen cierta relación con la de las mujeres que abren los ojos. La primera mujer está grabada en un plano picado, y como el personaje anterior, mira hacia arriba. Esta acción resulta enigmática para el espectador, quien no sabe a quién miran ambos personajes. Sin embargo, adquiere relevancia si se la sitúa junto al último plano de la película: la mujer abre los solo para evidenciar que estos ya estaban cerrados. Este gesto sobresalta al espectador que, por un segundo, siente haber perdido el control. Ahora es observado, ya no observa. Este plano niega al espectador la posibilidad de conocer a la mujer que cierra los ojos. De la relación entre la secuencia y la escena se puede extraer la siguiente cuestión: ¿quién está al otro lado del lente?

Durante la película, la pregunta parece no obtener respuesta, sin embargo, nace de un deseo que surge desde el espectador. La reacción que provoca Man Ray en el espectador en Emak Bakia retoma el motivo que el artista trabaja en su primer autorretrato y que desarrolla en las obras que hemos examinado como Le Vouyeur y Optic-Topic: el lugar de la mirada. En Emak Bakia, Man Ray lleva al espectador detrás de su propio lente, le habla íntimamente sobre el abandono del yo, la cesión del control que ejerce el ojo y cómo, a partir de gestos, los objetos cobran vida convirtiéndose en símbolos. Esto ocurre por la tensión que tiene el artista sobre los lugares que una persona puede ocupar frente o detrás de un lente, lo cual podríamos pensar como «el lugar de la imaginación». El último plano de Emak Bakia es el 
exponente más representativo de esta voluntad, razón por la cual ha sido tan comentado. En este plano, el artista demuestra saber encarnar su deseo de tal forma que el espectador se ve forzado a formar parte de él. En su Autorretrato Man Ray señala:

Para terminar la película hice un primer plano de Kiki. Me dio la idea su tendencia a maquillarse en exceso. Le dibujé un par de ojos artificiales sobre los párpados cerrados y los filmé; luego hice otra toma de sus ojos abiertos y le pedí que los fuese cerrando gradualmente. Sus labios se abrieron en una sonrisa que mostraba sus dientes uniformes. Y, con letras que se diluían, añadí: Finis (383).

De este modo, se establece una relación entre el primer plano de Emak Bakia, en el que el artista anuncia al espectador su posición ante la película, y el último plano, en el que se descubre el objeto de su deseo y que ha impulsado la visión. Este, al mismo tiempo, se convierte en deseo del espectador. Por esta razón, se puede decir que el surrealismo del filme recae en la voluntad de Man Ray de que el que mira el filme se convierta en participante de su propia visión durante el visionado del mismo.

\section{REFERENCIAS}

\section{Primaria}

Duchamp, Marcel, Man Ray y Francis Picabia. Duchamp, Man Ray, Picabia. Barcelona: Museu Nacional d'Art de Catalunya, 2008. Medio impreso.

---. Man Ray: Fotografías. Paris 1920-1934. Adreas Haus «Introducción». Barcelona: Grafos, 1980. Madio impreso.

---. Autorretrato. Barcelona: Alba Editorial, 2004. Medio impreso.

---. Man Ray: despreocupado pero no indiferente = unconcerned but not indifferent. Introducción de Don McCullin. Madrid: La Fábrica, 2007. Medio impreso.

---. et al. Man Ray: 60 anni de libertàl appunti biografici, bibliografia e un'antlogia di testi di Louis Aragon et al. Paris: Le Terrain Vague, 1971. Medio impreso.

\section{Secundaria}

Bourgeade, Pierre. Buenas noches, Man Ray: conversaciones con el artista. Madrid: La Fábrica, 2007. Medio impreso.

Cirlot, Victoria. Hildegard von Bingen y la tradición visionaria de Occidente. Barcelona: Herder, 2005. Medio impreso.

---. La visión abierta. Del mito del Grial al surrealismo. Madrid: Siruela, 2010. Medio impreso.

Company, Juan Migel. «Man Ray o el desdoblamiento del objeto». Surrealistas, surrealismo y cinema: curs. Barcelona: Fundació Caixa de Pensions, 1991. 131-147. Medio impreso. 
Hille, Karolina et al. (Eds.). Surreal objects: three-dimensional works from Dali to Man Ray. Frankfurt: Schirn Kunsthalle, 2011. Medio impreso.

Moholy-Nagy, László. Pintura, fotografía, cine y otros escritos sobre fotografía. Barcelona: Gustavo Gili, 2005. Medio impreso.

Penrose, Roland. Man Ray. London: Thames and Hudson, 1975. Medio impreso.

Petroni, Ilze Gabriela. Entre lo sacro y lo profano (bipótesis sobre cómo la fotografía ingresa en el campo del arte). San Juan: Jornadas Nacionales de Investigadores en Comunicación, 2006. Medio impreso.

Rondolino, Gianni. L'occhio tagliato: documenti del cinema dadista e surrealista. Torino: Martano Editore, 1972. Medio impreso.

Spies, Werner. Max Ernst: collages: the invention of the surrealist universe, London: Thames and Hudson, 1991. Medio impreso.

\section{Películas}

Ray, Man, dir. Le retour à la raison. 1923. Film.

---. Emak-Bakia. 1927. Film

---. L'étoile de mer. 1928. DVD.

---. Les Mystères du Château de Dé. Prod. Le Vicomte de Noailles. 1929. Film. 